\title{
Comparative study of metadiscourse markers employed in defense sessions of TEFL and Persian literature graduate students
}

Mahmoodian, Hamideh

English Department, Najafabad Branch, Islamic Azad University, Najafabad, Iran

Simin, Shahla $\triangle \Delta$

English Department, Najafabad Branch, Islamic Azad University, Najafabad, Iran (shahlasimin@yahoo.com)

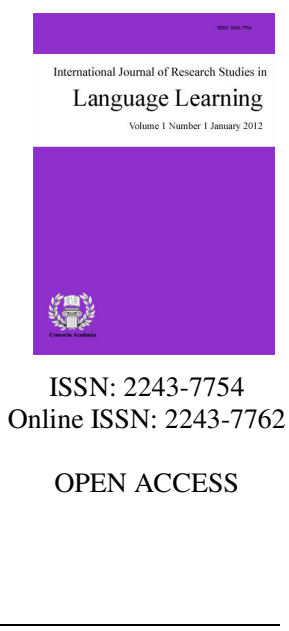

Received: 3 April 2017

Revised: 14 April 2017

Accepted: 18 April 2017

\section{Abstract}

This study aimed to explore the differences between TEFL and Persian literature graduate students in terms of applying metadiscourse markers in their oral presentations in defense sessions. The corpus of this study comprised the transcripts of oral presentations recorded in defense sessions of 30 graduate students, both male and female, from Islamic Azad University, Najaf Abad Branch, and it was divided into two parts of TEFL and Persian literature transcripts (each 15 transcripts). Based on Hyland's (2005) taxonomy, interactive and interactional metadiscourse markers were identified in transcripts and both descriptive and inferential statistics were utilized to analyze the data. According to the descriptive analysis, both TEFL and Persian literature graduate students employed interactive markers more frequently than interactional ones. Moreover, the use of interactive markers by Persian literature students was more than TEFL students, but the use of interactional markers was approximately similar for students in two disciplines. Regarding the inferential analysis, findings indicated that TEFL and Persian literature students were statistically different in terms of using different types of interactive and interactional markers. Nevertheless, there was a significant difference between TEFL and Persian literature students based on overall use of interactive markers and there was not observed any significant difference between them in terms of overall use of interactional ones. Generally, the results showed that Persian literature students applied metadiscourse markers more than TEFL students in their oral presentations. Findings of this study would be useful for teachers in guiding students to apply these markers in their speech to make it more coherent.

Keywords: metadiscourse; interactive metadiscourse markers; interactional metadiscourse markers 


\section{Comparative study of metadiscourse markers employed in defense sessions of TEFL and Persian literature graduate students}

\section{Introduction}

Academic theses are considered as academic texts written by university students in variety of subjects. According to Hyland (2004), "the dissertation is a high stake genre at the summit of a student's academic accomplishment" (p. 134). As writing an acceptable thesis in an academic setting depends on mastering writing skills to convey the accurate concept to the readers and to convince them, the oral presentation of thesis in defense session also requires the learning of oral skills to interact with the audiences and to persuade them. Being able to express a new point of view, to assert it, and to persuade audiences are necessary skills to enhance the quality of presentations in an academic setting. Lectures or oral presentations have monologue nature and they are common ways of transferring information to the listeners, thus the information which present in defense sessions must be acceptable and understandable for the audiences and motivate them to follow the presentation. Guiding a good lecture or presentation depends on the speaker's ability to control his/her speech and to interact with the audiences. Although, some skills involved in oral presentation depends on the speaker's personality, other skills are practical and can be learned. The use of metadiscourse markers is regarded as a practical factor in making the written or spoken text well-organized. As Swales (1990) states, the greater use of metadiscourse is the feature of the dissertation writing that makes it different, therefore the great function of metadiscourse in oral presentation of dissertation in defense session could not be ignored either.

According to Fraser (1988), the lack of discourse markers in a sentence does not make it ungrammatical or unintelligible, but it removes the cohesion and unity between the current utterance and previous discourse presented by the speaker. Accordingly, metadiscourse has the same function, it reflects the relationship between different parts of the discourse, and it shows "how the speaker intends the basic message that follows to relate to the prior discourse" (Schiffrin, 2001, p. 59). The function of metadiscourse is to add the cohesion and coherence to the discourse, and to connect the words and their meanings together, and to make the speech more comprehensible for the audience.

Metadiscourse markers play a significant role in written and spoken academic texts, because they explain how writers and speakers "present and negotiate propositional information in ways that are meaningful and appropriate to a particular disciplinary community" (Hyland, 2004, p.136). Hyland and Tse (2004) and Hyland (2005) state that writing or speaking is considered as a social communicative process between writers and readers or speakers and listeners. In this regard, when writers and speakers use metadiscourse markers in their written or spoken text, they communicate with their receivers in a meaningful way. By using metadiscourse markers, speakers and presenters can choose the appropriate components of language and organize them in a way that they intend to share with the listeners. Therefore, metadiscourse is significant in organizing the discourse, involving the audience, and signaling the attitude of writers or speakers (Fuertes-Olivera, Velasco-sacristan, Arribas-Bano, \& Samaniego-Fernandez, 2001). According to Hyland (2005), "Metadiscourse is the cover term for the self-reflective expressions used to negotiate interactional meanings in a text, assisting the writer or speaker to express a viewpoint and engage with readers as members of a particular community" (p. 37). Metadiscourse markers help the speaker to express his/her attitude toward the proposition to attract the listeners' attention and to help them comprehend the discourse better. Metadiscourse emphasizes that when we write or speak we interact with others and make some decisions about our effects on the listeners or readers (Hyland, 2005).

Simin and Tavangar (2009) in their article ' metadiscourse knowledge and use in Iranian EFL writing' referred to the great importance of metadiscourse in writing and they believed that the use of metadiscourse markers is related to the language proficiency of learners. They mentioned that more proficient learners apply 
metadiscourse markers more frequent than other learners in their written texts.

According to Ghaemi and Naderi Anari (2014), metadiscourse plays a pragmatic role in that it makes a relationship between speaker and listener, and reflects the speaker's intention. They commented that lectures are more comprehensible when metadiscourse markers are included because they make the text more coherent and understandable for the audience. They also mentioned that the lack of metadiscourse markers prevent the semantic relationship between different parts of the text. Hyland and Tse (2004) refer to the term metadiscourse "as aspect of language which provides a link between text and disciplinary culture, helping to define the rhetorical context by revealing some of the expectations and understandings of the audience for whom a text was written" (p. 175).

Metadiscourse is understood across some linguistic features that are included in the interpersonal metadiscourse model (Hyland, 2005). Hyland (1999) believed that interpersonal metadiscourse lets authors to present their point of view toward the readers and the propositional content and "it is essentially an evaluative form of discourse and expresses the writer's individually defined, but disciplinary circumscribed, persona" (p.8). Metadiscourse is considered as interpersonal resources that are necessary to organize a text or the status of writer toward the content and the reader (Hyland, 2000). Interpersonal features "allow writers to express a perspective toward their propositional information and their readers" (Hyland, 1999, p.7). Hyland and Tse (2004) state that "all metadiscourse is interpersonal in that it takes account of the reader's knowledge, textual experience, and processing needs" (p. 161). Hyland and Tse (2004) and Hyland (2005) proposed two dimensions of metadiscourse; interactive and interactional metadiscourse markers. According to Hyland and Tse (2004), interactive metadiscourse markers refer to the ways of discourse organization, and they guide what can be received from the text. Interactive metadiscourse are "features used to organize propositional information in ways that the target reader should find coherent and convincing" (Hyland, 2005, p. 50). Regarding these definitions, they proposed five subcategories for interactive metadiscourse markers; transitions, frame markers, endophoric markers, evidentials, and code glosses. Hyland and Tse (2004) defined these subcategories of interactive metadiscourse markers as follow:

$>$ Transitions which include conjunctions and apply to marking additive, comparative, and consequential sorts.

$>\quad$ Frame markers are elements of schematic text structure, consisting items utilized to sequence, to label text steps, to notify discourse objectives, and to reveal topic shift.

$>$ Endophoric markers provide additional material to the reader in order to clarify the writer's intention.

$>$ Evidentials represent the source of textual information which is available outside the current text.

$>$ Code glosses express the ideational information through the text in other ways.

On the other hand, Hyland and Tse (2004), comment that interactional metadiscourse markers engage readers into the argument and make them aware about the writer's view toward propositional information and readers. Interactional metadiscourse "draw the reader into the discourse and give them an opportunity to contribute to it and respond to it by alerting them to the writer's perspective on propositional information and orientation and intention with respect to that reader" (Hyland, 2005, p. 52). Interactional metadiscourse markers include hedges, boosters, attitude markers, self-mention, and engagement markers. According to Hyland and Tse (2004), different subcategories of interactional markers are presented as below:

$>$ Hedges that show the writer's reluctance to providing propositional information systematically.

$>$ Boosters reflect certainty and they focus on the force of prepositions.

$>$ Attitude markers represent the writer's appraisal of propositions; they express obligation, importance, surprise, and etc.

$>\quad$ Self-mentions refer to the degree of writer's presence based on first person pronouns and possessives occurrence.

$>$ Engagement markers directly address the reader in the text with imperative, question forms, second person pronouns, and so on.

Oral presentation and lecture are main tasks which are necessary for all academic courses. The majority of 
Mahmoodian, H., \& Simin, S.

academic students have some problems with giving the lecture and interacting with their audiences. Awareness of the appropriate use of metadiscourse markers in speaking can help the students make their oral presentations and lectures more meaningful and more coherent. This research focuses on metadiscourse markers as necessary tools for making interaction between the speaker and audience easier. By removing metadiscourse markers from speaking, speech becomes less comprehensible. Thus, research on the appropriate ways of using metadiscourse markers will guide the students understand the right meanings of these markers for different academic discourses. Many studies have been done on the role and effect of metadiscourse markers in various written texts and genres but the important role of these markers in speaking and oral presentation is ignored and little attention is paid to their usage in speaking. Therefore, exploring the role of interactive and interactional metadiscourse markers in oral presentations is essential to determine the importance of these markers in enhancing the comprehensibility and quality of presentations.

This study is conducted to find variations between TEFL and Persian literature graduate students in terms of using metadiscourse markers in their oral presentations in defense sessions. It also aims to examine the frequency and importance of various types of metadiscourse markers used in oral presentation of graduate students in order to persuade their audiences. In fact, this study investigates the interactive and interactional metadiscourse markers based on Hyland's (2005) metadiscourse model. The results of this study can raise Iranian university students' consciousness in the process of using metadiscourse markers as an important mean in speaking. The findings of this study will also guide the students to organize their academic speech and presentation by appropriate use of metadiscourse markers. In line with the study, the following research questions were posed:

$>$ Is there any significant difference between TEFL and Persian literature graduate students in terms of the overall use of metadiscourse markers in oral presentation of their thesis in defense sessions?

$>$ Is there any significant difference between TEFL and Persian literature graduate students in terms of using interactive markers in oral presentation of thesis in defense sessions?

$>$ Is there any significant difference between TEFL and Persian literature graduate students in terms of using interactional markers in oral presentation of thesis in defense session?

\section{Method}

\subsection{Research Corpus}

The corpus of this study was a set of data composed of 30 transcripts of oral presentations recorded in defense sessions of graduate students, both male and female. The defense sessions of 15 TEFL graduate students and 15 Persian literature graduate students were selected from Islamic Azad University of Najaf Abad, Iran. The oral presentations of students in their defense sessions were recorded and transcribed by the researcher. Then, these transcripts were divided into two parts: oral presentations of TEFL students (25067 words) and oral presentations of Persian literature students (13853 words). Afterward, they were analyzed carefully to find out the types and frequencies of interactive and interactional metadiscourse markers in accordance with Hyland's (2005) interpersonal model.

\subsection{Research Instrument}

An interpersonal model of Hyland (2005) was employed as an instrument to analyze interactive and interactional metadiscourse markers used in oral presentations of TEFL and Persian literature graduate students in their defense sessions. Hyland's (2005) model in categorizing metadiscourse markers (2005) is as follow: 
Metadiscourse markers employed in defense sessions of TEFL and Persian literature graduate students

Table 1

An Interpersonal Model of Metadiscourse Markers (Hyland, 2005, p. 49)

\begin{tabular}{|c|c|c|}
\hline Category & Function & Examples \\
\hline Interactive & Help to guide the reader through the text & \\
\hline Transitions & Express semantic relation between main clauses & In addition/ but/ thus/ and \\
\hline Frame markers & Refer to discourse acts, sequences or stages & Finally/to conclude/ my purpose is \\
\hline Endophoric markers & Refer to information in other parts of text & Noted above/ see figure/ in section 2 \\
\hline Evidential & Refer to information from other text & According to $\mathrm{X} / \mathrm{Z}$ states \\
\hline Code glosses & Help readers grasp functions of ideational meaning & Namely/ e.g./ such as/ in other words \\
\hline Interactional & Involve the reader in the argument & \\
\hline Hedges & Withhold writer's full commitment to proposition & Might/perhaps/possible/about \\
\hline Boosters & Emphasize force or writers' certainty in proposition & In fact/definitely/it is clear that \\
\hline Attitude markers & Express writer's attitude to proposition & Unfortunately/I agree/surprisingly \\
\hline Self- mention & Explicit reference to author(s) & I/we/my/our \\
\hline Engagement markers & Explicitly refer to or build relationship with reader & Consider/note that/you can see that \\
\hline
\end{tabular}

\subsection{Procedure}

The data of present study were collected between December and February in 2015. In order to conduct the study, 15 defense sessions of TEFL graduate students and 15 defense sessions of Persian literature graduate students, both male and female, were selected from Islamic Azad University of Najaf Abad, Iran. The time allocated to each student to defend his/her thesis was about 20 minutes. The researcher attended in these sessions and recorded the oral presentations of the students by a tape recorder. The permission of attending in defense sessions and recording the voice of each student was taken from the heads of TEFL and Persian literature departments and also from each student separately. In order to observe the ethical issues, each presentation was given a code. Then, the collected recordings were transcribed word by word and divided into two parts of TEFL and Persian literature oral presentations. Afterward, the transcripts were analyzed by the researcher to explore the type and frequency of interactive and interactional metadiscourse markers according to Hyland's (2005) interpersonal model. All markers were counted manually and were analyzed twice by the researcher to avoid any fault in counting them. Also, they were checked by a university lecturer who was an expert in the area of metadiscourse markers and their applications. Then, the inter-rater reliability was calculated and confirmed $(88 \%)$. Finally, the frequency and type of these metadiscourse markers were compared between TEFL and Persian literature graduate students.

\subsection{Data Analysis}

The oral presentations of 15 TEFL graduate students and 15 Persian literature graduate students were recorded in their defense sessions. Then, these recordings were transcribed by the researcher and divided into two parts: TEFL (25067 words) and Persian literature (13853 words) transcripts. Afterward, they were read word by word carefully to identifying the types of interactive and interactional metadiscourse markers in terms of Hyland's (2005) interpersonal model and their frequencies were counted manually. These transcripts were analyzed twice by the researcher and were checked by a university lecturer who was expert in the area of metadiscourse markers studies based on Hyland's (2005) model. Since two parts of the corpus did not have the same length, thus in order to ensure the comparability of them based on the proportion of metadiscourse elements' numbers to the total number of words, 1000-words approach (instances per 1000 words) was utilized. Therefore, after identifying and counting the frequency of different types of metadiscourse markers and checking their reliability based on inter-rater reliability (88\%), their frequencies were calculated in terms of the occurrence of metadiscourse elements per 1000 words.

The analysis of quantitative data used in this study was based on SPSS software, version 21. The data were analyzed by using both descriptive and inferential statistics methods. To analyze the frequency of interactive and interactional metadiscourse markers used by candidates, the descriptive statistic method was used. To see if there 
Mahmoodian, H., \& Simin, S.

are any statistically significant differences in the use of these markers by TEFL and Persian literature graduate students, the inferential statistic method like independent sample t-test was run.

\section{Results}

The corpus of present study included the transcripts of oral presentations recorded in defense sessions of 30 graduate students and it contained two parts: 15 transcripts of oral presentations by TEFL students (25067 words), and 15 transcripts of oral presentations by Persian literature students (13853 words). The descriptive statistics of the corpus is presented in Table 2 .

Table 2

Descriptive Statistics of the Corpus

\begin{tabular}{lccc}
\hline \multicolumn{1}{c}{ Transcripts } & Number & Number of words & Mean of words \\
\hline TEFL & 15 & 25067 & 1671.13 \\
Persian literature & 15 & 13853 & 929.53 \\
Total & 30 & 38920 & 2600.66 \\
\hline
\end{tabular}

Based on the statistics presented in Table 2, the number of words of TEFL transcripts is more and approximately twice than the number of words of Persian literature transcripts. Also, the mean of words in TEFL transcripts is higher than Persian literature transcripts (1671.13>929.53). Since two parts of the corpus did not have the same length, in order to ensure the comparability of these two parts based on the proportion of metadiscourse elements' numbers to the total number of words, 1000-words approach (instances per 1000 words) was utilized. This common approach was used by many scholars in the area of metadiscourse (e. g., Hyland, 1998, 2004; Crismore, Markkanen, \& Steffensen, 1993; Hyland \& Tse, 2004). Therefore, after identifying and counting the frequency of different types of metadiscourse markers in each transcript, their frequencies were calculated in terms of the occurrence of metadiscourse elements per 1000 words. First, before analyzing the data to answer the research questions, their distribution was analyzed by using Shapiro-Wilk test to ensure that they are compatible with the assumption of normality. The results of Shapiro-Wilk test are presented in Table 3.

\section{Table 3}

Results of Shapiro-Wilk Test to Analyze the Normality of Quantitative Data

\begin{tabular}{|c|c|c|c|c|c|c|}
\hline \multirow[t]{2}{*}{ Markers } & \multicolumn{3}{|c|}{ TEFL transcripts } & \multicolumn{3}{|c|}{ Persian literature transcripts } \\
\hline & Statistics & df & Sig. & Statistics & $\mathrm{df}$ & Sig. \\
\hline Transitions & .966 & 15 & .798 & .929 & 15 & .262 \\
\hline Frame markers & .953 & 15 & .573 & .937 & 15 & .351 \\
\hline Endophorics & .930 & 15 & .273 & .881 & 15 & .050 \\
\hline Evidentials & .902 & 15 & .101 & .918 & 15 & .177 \\
\hline Code glosses & .970 & 15 & .862 & .963 & 15 & .741 \\
\hline Total interactives & .927 & 15 & .250 & .988 & 15 & .988 \\
\hline Hedges & .926 & 15 & .238 & .897 & 15 & .087 \\
\hline Boosters & .948 & 15 & .486 & .908 & 15 & .124 \\
\hline Attitude markers & .921 & 15 & .200 & .883 & 15 & .052 \\
\hline Self-mentions & .956 & 15 & .621 & .904 & 15 & .109 \\
\hline Engagement markers & .913 & 15 & .151 & .885 & 15 & .056 \\
\hline Total interactionals & .938 & 15 & .357 & .942 & 15 & .408 \\
\hline Total & .951 & 15 & .534 & .976 & 15 & .933 \\
\hline
\end{tabular}

As it is shown in Table 3, regarding the frequency of different types of metadiscourse markers employed in oral presentations of TEFL and Persian literature students, the significant level of Shapiro-Wilk test to analyze the assumption of normality for different types of metadiscourse markers is greater than 0.05 . Therefore, it can be claimed that the distribution of different types of metadiscourse markers applied in oral presentations of both groups of students is normal. 


\subsection{Results for the First Research Question}

The first research question of this study addressed the difference between TEFL and Persian literature graduate students in terms of overall use of metadiscourse markers in oral presentation of thesis in defense session. Table 4 reports the descriptive statistics which compares metadiscourse markers applied in oral presentations of TEFL and Persian literature students.

\section{Table 4}

Descriptive Statistics for Metadiscourse Markers Used (Per 1000 Words)

\begin{tabular}{lcccccccc}
\hline & \multicolumn{3}{c}{ TEFL students } & \multicolumn{4}{c}{ Persian literature students } \\
\cline { 2 - 9 } & Min & Max & M & SD & Min & Max & M & SD \\
\hline Interactive & 71.65 & 108.52 & 85.01 & 10.95 & 64.10 & 143.16 & 100.71 & 20.48 \\
Interactional & 16.47 & 49.42 & 32.30 & 9.28 & 9.27 & 69.83 & 32.44 & 17.49 \\
Total & 95.52 & 151.23 & 117.31 & 16.13 & 93.29 & 167.84 & 133.15 & 21.44 \\
\hline
\end{tabular}

According to the statistics presented in Table 4, the frequency mean of interactive markers applied in oral presentations of both TEFL and Persian literature students was higher than the frequency mean of interactional markers. However, interactive markers were applied in oral presentations of Persian literature students more than TEFL students (100.71>85.01 per 1000 words). Generally, the frequency range of all metadiscourse markers employed by TEFL students was estimated between 95.52 and 151.23, and by Persian literature students was between 93.29 and 167.84 per 1000 words. Comparing the mean of total metadiscourse markers applied in oral presentations of students revealed that metadiscourse elements were used by Persian literature students with the mean of 133.15 more than TEFL students with the mean of 117.31. Figure 1 shows the mean difference of total numbers of metadiscourse markers applied in oral presentations of two groups of students.

Figure 1. Mean of total numbers of metadiscourse markers employed in oral presentations of TEFL and Persian literature

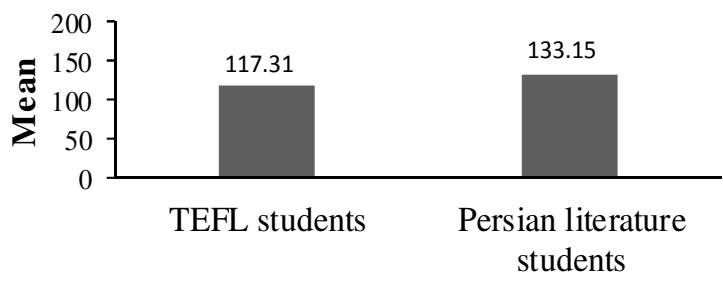
students (Per 1000 Words).

Group

As depicted in Figure 1, the mean of metadiscourse markers employed by Persian literature students (133.15) is higher than TEFL students (117.31). The mean difference of metadiscourse markers applied by two groups of students is 15.84 which appear to be statistically significant. Thus, it clearly indicates that TEFL and Persian literature students are different in terms of overall use of metadiscourse markers in their oral presentations. Therefore, in order to see if there is significant difference between TEFL and Persian literature students in terms of overall use of metadiscourse markers, the independent sample t-test was run. The result of independent sample t-test is shown in Table 5.

\section{Table 5}

T- Test to Compare the Total Mean of Metadiscourse Markers

\begin{tabular}{cccccc}
\hline & $\mathrm{t}$ & $\mathrm{df}$ & Sig. (2-tailed) & Mean Difference & $\begin{array}{c}\text { Std. Error } \\
\text { Difference }\end{array}$ \\
\hline $\begin{array}{c}\text { Total } \\
\text { metadiscourse } \\
\text { markers }\end{array}$ & -2.29 & 28 & .030 & -15.84 & 6.93 \\
\hline
\end{tabular}

Based on the results of Table 5, the comparison of metadiscourse markers' mean indicated that there exists significant difference between TEFL and Persian literature students in terms of overall use of metadiscourse markers in their oral presentations. According to the result of independent sample t-test, the level of significance 
Mahmoodian, H., \& Simin, S.

is 0.03 which is lower than the identified level of significance $(p<0.05)$.

\subsection{Results for the Second Research Question}

The second research question attempted to find any significant difference between TEFL and Persian literature graduate students in terms of using interactive markers in oral presentation of thesis in defense session. Table 6 shows the categorical comparison of interactive markers applied in oral presentations of TEFL and Persian literature students.

\section{Table 6}

Descriptive Statistics for Interactive Markers Employed in Oral Presentations of TEFL and Persian Literature Students (Per 1000 Words)

\begin{tabular}{lcccccccc}
\hline \multirow{1}{*}{\multicolumn{1}{c}{ Interactive }} & \multicolumn{3}{c}{ TEFL students } & \multicolumn{4}{c}{ Persian literature students } \\
\cline { 2 - 9 } \multicolumn{1}{c}{ markers } & Min & Max & M & SD & Min & Max & M & SD \\
\hline Transitions & 40.74 & 74.09 & 58.58 & 9.36 & 38.46 & 104.09 & 77.80 & 19.52 \\
Frame markers & 6.35 & 26.43 & 14.60 & 5.21 & 3.09 & 26.57 & 11.75 & 6.92 \\
Endophorics & 0.00 & 5.50 & 2.82 & 1.72 & 0.00 & 3.30 & 1.39 & 1.04 \\
Evidentials & 0.56 & 4.25 & 1.97 & 1.16 & 0.00 & 5.76 & 2.35 & 1.58 \\
Code glosses & 0.49 & 12.33 & 7.05 & 3.24 & 0.00 & 15.08 & 7.43 & 4.52 \\
Total & 71.65 & 108.52 & 85.01 & 10.95 & 64.10 & 143.16 & 100.71 & 20.48 \\
\hline
\end{tabular}

As it is clearly shown in Table 6, among interactive markers employed in oral presentations of TEFL students, transitions obtained the highest mean (58.58 per 1000 words) and evidentials gained the lowest mean (1.97 per 1000 words). While, transitions were used as the most frequent marker with the mean of 77.80 and endophorics were applied as the less frequent marker with the mean of 1.39 by Persian literature students. Regarding the mean of overall use of interactive markers, Persian literature students applied interactive markers more frequently than TEFL students (100.71>85.01 per 1000 words). Figure 2 shows the categorical comparison of interactive markers employed by TEFL and Persian literature students in their oral presentations.

Figure 2. Mean of interactive markers employed in oral presentations of TEFL and Persian literature students (Per 1000 Words)

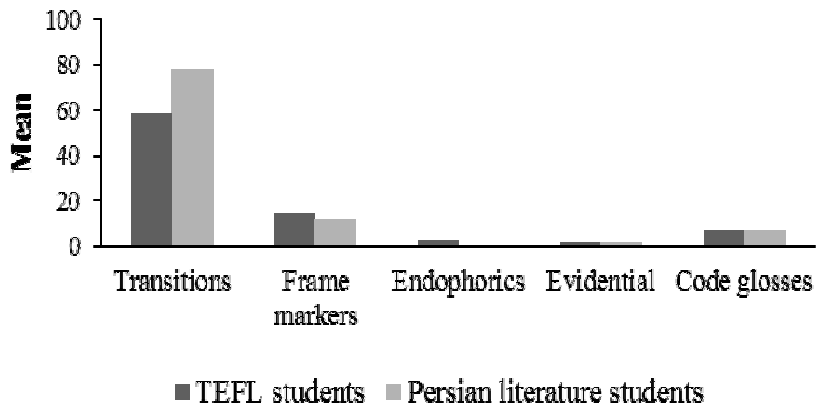

As it is illustrated in Figure 2, among subcategories of interactive metadiscourse markers employed in oral presentations of both TEFL and Persian literature students, the highest mean belongs to transitions and the lowest mean relates to evidentials and endophorics. Figure 3 shows the overall comparison of interactive markers employed in oral presentations of two groups of students.

Figure 3. Mean of total numbers of interactive markers employed in oral presentations of TEFL and Persian literature students (Per 1000 Words)

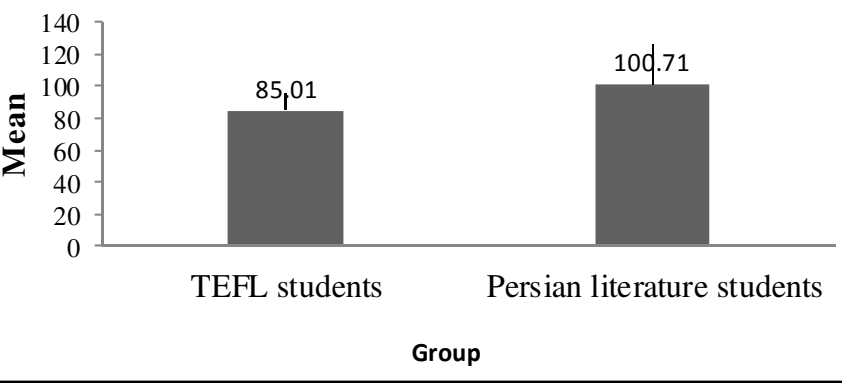

72 Consortia Academia Publishing 
Metadiscourse markers employed in defense sessions of TEFL and Persian literature graduate students

As it is shown in above figure, comparing the overall use of interactive markers by two groups of students showed that Persian literature students employed interactive markers more than TEFL students in their oral presentations.

In order to answer the second research question, the independent sample t-test test was used to analyze the data. Table 7 reports the results of inferential analysis performed to compare the means of different types of interactive markers between TEFL and Persian literature students.

Table 7

T-Test to Compare the Mean of Interactive Markers Used

\begin{tabular}{lccccc}
\hline Interactive markers & $\mathrm{t}$ & $\mathrm{df}$ & Sig. (2-tailed) & Mean Difference & $\begin{array}{c}\text { Std. Error } \\
\text { Difference }\end{array}$ \\
\hline Transitions & -3.44 & 28 & .002 & -19.22 & 5.59 \\
Frame markers & 1.275 & 28 & .213 & 2.85 & 2.24 \\
Endophorics & 2.75 & 28 & .010 & 1.43 & .51 \\
Evidentials & -.75 & 28 & .460 & -.38 & .51 \\
Code glosses & -.26 & 28 & .794 & -.38 & 1.44 \\
Total & -2.62 & 28 & .014 & -15.70 & 5.99 \\
\hline
\end{tabular}

The findings in Table 7 indicate that there exists significant difference between TEFL and Persian literature students in two subcategories of interactive markers $(p<0.05)$, namely, transitions and endophorics. As it was earlier shown in Table 6, the mean of transitions used by Persian literature students was significantly more than TEFL students (77.80>58.58 per 1000 words), while the mean of endophorics applied by Persian literature students was statistically less than TEFL students $(1.39<2.82$ per 1000 words). In other three subcategories of interactive markers, such as frame markers, evidentials, and code glosses there was not any significant difference between TEFL and Persian literature students $(p>0.05)$. Regarding the overall use of interactive markers in oral presentations, the results of independent sample t-test indicated that there is significant difference between TEFL and Persian literature students $(0.01<0.05)$.

\subsection{Results for the Third Research Question}

The third research question referred to the difference between TEFL and Persian literature graduate students in terms of using interactional markers in oral presentation of thesis in defense session. Descriptive analysis was used to compare the use of interactional markers employed by TEFL and Persian literature students. The results are presented in Table 8 .

\section{Table 8}

Descriptive Statistics for Interactional Markers Employed (Per 1000 Words)

\begin{tabular}{lcccccccc}
\hline & \multicolumn{3}{c}{ TEFL students } & \multicolumn{4}{c}{ Persian literature students } \\
\cline { 2 - 9 } \multicolumn{1}{c}{ Interactional markers } & Min & Max & M & SD & Min & Max & M & SD \\
\hline Hedges & 2.86 & 10.71 & 7.10 & 2.41 & 0.00 & 12.07 & 4.20 & 4.07 \\
Boosters & 2.15 & 10.73 & 6.46 & 2.79 & 1.37 & 9.53 & 4.26 & 2.49 \\
Attitude markers & 0.00 & 4.12 & 1.81 & 1.40 & 0.00 & 3.09 & 1.04 & 0.84 \\
Self-mentions & 2.06 & 23.89 & 10.86 & 5.61 & 0.00 & 53.67 & 17.05 & 13.72 \\
Engagements & 0.00 & 18.22 & 6.06 & 4.57 & 0.00 & 19.23 & 5.90 & 5.63 \\
Total & 16.47 & 49.42 & 32.30 & 9.28 & 9.27 & 69.83 & 32.44 & 17.49 \\
\hline
\end{tabular}

As it is presented in Table 8, considering the means of interactional markers used in oral presentations, both TEFL and Persian literature students employed self-mentions as the most proportion. However, Persian literature students applied more self-mentions (17.05 per 1000 words) comparing to TEFL students (10.86 per 1000 words). In contrast, among interactional markers applied by both groups of students, the lowest mean belongs to attitude markers. As shown in Table 8, the mean of attitude markers used by TEFL students was 1.81 per 1000 words and by Persian literature students was 1.04 per 1000 words. Generally, among interactional markers 
Mahmoodian, H., \& Simin, S.

applied in oral presentations of TEFL and Persian literature students, the highest proportion belongs to self-mentions and the lowest proportion relates to attitude markers.

According to the Table 8, the mean of total numbers of interactional markers used in oral presentations of TEFL students was between 16.47 and 49.42 per 1000 words, while for Persian literature students it was between 9.27 and 69.83 per 1000 words. But the difference between TEFL and Persian literature students in terms of comparing the total mean of interactional markers was not significantly different $(32.30,32.44$ per 1000 words respectively). Figure 4 compares the subcategories of interactional metadiscourse markers applied in oral presentations of TEFL and Persian literature students.

Figure 4. Mean of interactional markers employed in oral presentations of TEFL and Persian literature students (Per 1000 Words)

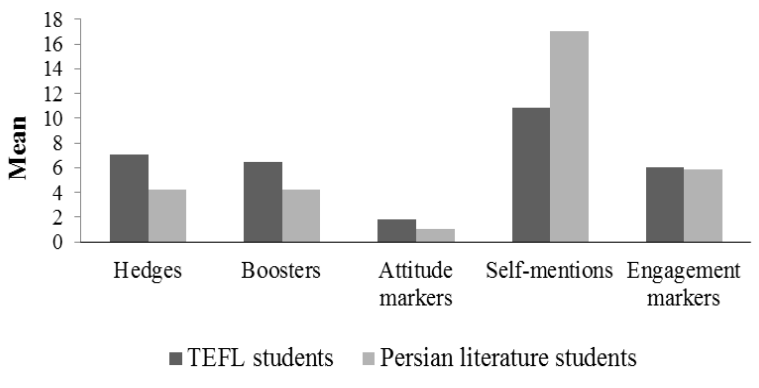

As shown in Figure 4, among categories of interactional markers employed by both TEFL and Persian literature students, the highest mean belongs to self-mentions and the lowest mean relates to attitude markers. And except in the case of self-mentions, in the other four cases, TEFL students employed interactional markers more than Persian literature students. Figure 5 depicts the overall use of interactional markers in oral presentations of students.

Figure 5. Mean of total numbers of interactional markers employed in oral presentations of TEFL and Persian literature students (Per 1000 Words)

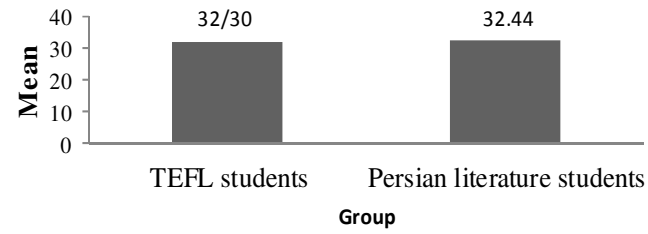

Based on Figure 5, the overall use of interactional markers by both TEFL and Persian literature students was approximately similar. Therefore, it can be claimed that the difference between TEFL and Persian literature students in terms of overall use of interactional markers in their oral presentations was not significant. Table 9 shows the results of inferential analysis.

Table 9

T-Test results of the Interactional Markers Used in Oral Presentation of TEFL and Persian Literature Students

\begin{tabular}{lccccc}
\hline \multicolumn{1}{c}{ Interactional markers } & $\mathrm{t}$ & $\mathrm{df}$ & $\begin{array}{c}\text { Sig. } \\
\text { (2-tailed) }\end{array}$ & Mean Difference & $\begin{array}{c}\text { Std. Error } \\
\text { Difference }\end{array}$ \\
\hline Hedges & 2.37 & 22.72 & .027 & 2.90 & 1.22 \\
Boosters & 2.28 & 28 & .030 & 2.19 & .97 \\
Attitude markers & 1.84 & 22.83 & .080 & .77 & .42 \\
Self-mentions & -1.62 & 18.56 & .123 & -6.18 & 3.83 \\
Engagement markers & .09 & 28 & .929 & .17 & 1.87 \\
Total & -.03 & 21.31 & .978 & -.14 & 5.11 \\
\hline
\end{tabular}

According to the results presented in Table 9, among subcategories of interactional metadiscourse markers, there was significant difference between TEFL and Persian literature students in terms of their using of hedges and boosters. As can be seen, in the case of hedges, the significant level is $0.02<0.05$ and in the case of boosters, the significant level is $0.03<0.05$. On the contrary, in cases of attitude markers, self-mentions, and engagement markers there was not any significant difference between TEFL and Persian literature students $(\mathrm{p}>0.05)$. Regarding the overall use of interactional markers, the $\mathrm{p}$ value in Sig. (2-tailed) column was higher than the 
Metadiscourse markers employed in defense sessions of TEFL and Persian literature graduate students

specified level of significance $(0.97>0.05)$. Therefore, it can be concluded that there is not any significant difference between TEFL and Persian literature students in terms of overall use of interactional markers in their oral presentation in defense sessions.

\section{Discussion}

Regarding the first and second research questions of the study and according to the statistics, conclusions were made that there is significant difference between TEFL and Persian literature graduate students in terms of overall use of metadiscourse markers and also the use of interactive markers in their oral presentations in defense sessions. While, with regard to the third research question, results indicated that there is not any significant difference between TEFL and Persian literature graduate students in terms of applying interactional markers in their oral presentations in defense sessions.

Concerning the descriptive analysis of first research question and based on the findings of the study, TEFL and Persian literature students were different in terms of using metadiscourse markers in their oral presentations. Comparing the means of interactive and interactional markers applied in oral presentations revealed that both TEFL and Persian literature students employed interactive markers more than interactional ones. With regard to the mean of total numbers of metadiscourse markers, it could be inferred that Persian literature students applied metadiscourse markers more than TEFL students in their oral presentations (133.15>117.31 per 1000 words). In Figure 1, the mean difference of overall use of metadiscourse markers by two groups of students was clearly shown and it was estimated about 15.84 which appear to reach statistical significance. In addition, the inferential statistics reported in Table 4 indicated that TEFL and Persian literature students are significantly different in terms of overall use of metadiscourse markers in their oral presentations in defense sessions.

Regarding the descriptive analysis of second research question, findings revealed that among subcategories of interactive markers applied in oral presentations of students, transitions reached the highest mean by both TEFL (58.58 per 1000 words) and Persian literature students (77.80 per 1000 words). But the lowest mean of applied interactive markers by TEFL students was belonged to evidentials (1.97 per 1000 words) and by Persian literature students was related to endophorics (1.39 per 1000 words). In general, the comparison of total mean of interactive markers' use between two groups of students showed that Persian literature students employed interactive markers more frequently than TEFL students in their oral presentations $(100.71>85.01$ per 1000 words). As shown by the results of the study, the mean of total numbers of interactive markers used by Persian literature students is higher than TEFL students.

Based on inferential statistics of research question two, there was significant difference between TEFL and Persian literature students in just two cases of interactive markers, namely transitions and endophorics. While in other cases of interactive markers such as frame markers, evidential, and code glosses, there was not observed any significant difference between two groups of students. In sum, comparing the total mean of interactive markers indicated that TEFL and Persian literature students were statistically different in terms of using these markers in their oral presentations $(p<0.05)$.

Considering the descriptive statistics of third research question, the results indicated that among interactional markers used in oral presentations, self-mentions were used more than other markers by both TEFL and Persian literature students (10.86, 17.05 per 1000 words respectively). In contrast, attitude markers were applied as the less frequent marker in oral presentations of TEFL and Persian literature students (1.81, 1.04 per 1000 words respectively). Generally, based on Figure 5, the overall use of interactional markers by both TEFL and Persian literature students was approximately similar and this resulted in the lack of statistical difference between two groups of students.

With regard to the inferential analysis of research question three, among subcategories of interactional metadiscourse markers, there was significant difference between TEFL and Persian literature students in terms of their using of hedges and boosters. But in the cases of attitude markers, self-mentions, and engagement markers 
Mahmoodian, H., \& Simin, S.

there was not any significant difference between TEFL and Persian literature students. Although, there were some differences in the use of subcategories of interactional markers by TEFL and Persian literature students, there was not statistically significant difference between TEFL and Persian literature students in terms of overall use of interactional markers in their oral presentations.

The findings of present study are compatible with the results of previous studies (Faghih \& Rahimpour, 2009; Zarei \& Mansoori, 2011; Estaji \& Vafaeimehr, 2015), while they are contrary to some other studies (Kuhi \& Mojood, 2012; Gholami, Tajalli, \& Shokrpour, 2014; Rezaeizadeh, Baharlooei, \& Simin, 2015). Kuhi and Mojood (2012) referred to interactional markers as predominant category of metadiscourse markers and attitude markers as a predominant subcategory of interactional markers in English and Persian editorials. Besides, Gholami et al. (2014) concluded that interactional markers were used more than interactive markers in both English medical texts and their Persian translations. Another study by Rezaeizadeh et al. (2015) demonstrated that the frequency of interactional markers was more than interactive markers in English teaching, English literature, and English translation master theses written by Iranian EFL learners.

In line with findings of this study, Zarei and Mansoori (2011) concluded that metadiscourse markers were used in Persian articles more frequent than English articles in two disciplines of applied linguistic and computer engineering. In another study, Faghih and Rahimpoor (2009) found that Iranian and English academic writers applied interactive markers more than interactional ones in discussion sections of their applied linguistic articles. Also, the results obtained by Estaji and Vafaeimehr (2015) demonstrated that there was no significant difference between mechanical and electrical engineering articles written by English native speakers in terms of using interactional markers.

\section{Conclusion}

Hyland (1998) defined metadiscourse as "a ubiquitous aspect of our everyday language, and a main feature of the ways we communicate in a range of genre and settings." (p. 438). He believed that academic communication is a social act which functions to facilitate the process of knowledge production in a disciplinary community and convincing an academic audience of the trueness of writer's or speaker's arguments require making some linguistic choices which that audience will identify as persuasive. He also suggested that metadiscourse can be considered as a mean of facilitating the social communications which involves in production of knowledge within academic disciplines.

Hyland (2005) believed that metadiscourse is an umbrella cover which alludes to self-reflective terms applied to exchange the meaning through the text, help the author to express his or her viewpoints and involve readers as members of a particular society. He commented that by using metadiscourse markers, readers or listeners become able to reconstruct the structure of the text, recognize the logical relation of contents, process the information, and identify those concepts involved in communication of meaning.

With regard to the categorical distribution of metadiscourse markers in oral presentations of TEFL and Persian literature students, interactive metadiscourse markers were used as most proportion by students of two disciplines comparing to interactional ones. Considering the overall distribution of metadiscourse markers in oral presentations, descriptive analysis revealed that metadiscourse markers were employed in oral presentations of Persian literature students more than TEFL students.

Regarding the overall use of interactive and interactional metadiscourse markers, the results of descriptive analysis indicated that there was significant difference between TEFL and Persian literature students in terms of overall use of interactive markers, while there was not any significant difference between students of two disciplines based on overall use of interactional ones. Interactive markers applied in oral presentations of Persian literature students were more than TEFL students, but the use of interactional markers between two groups of students was approximately similar. 
Metadiscourse markers employed in defense sessions of TEFL and Persian literature graduate students

Concerning the differences between TEFL and Persian literature students in terms of categorical use of interactive and interactional metadiscourse markers, inferential analysis demonstrated that there was significant difference between TEFL and Persian literature students based on using two cases of interactive markers, namely transitions and endophoric markers, and the significant difference between TEFL and Persian literature students in terms of using subcategories of interactional markers was belonged to hedges and boosters.

\subsection{Implications of the Study}

The findings of this study can be beneficial for presenters of master and doctoral theses to attract the attention of their audiences in defense sessions. University students in different English and Persian fields of study must pay attention to the role and function of interactive and interactional metadiscourse markers in oral presentation and speech. They should be encouraged to apply metadiscourse markers in their speech to make it more coherent and comprehensible. Moreover, the results of present study can be important for lecturers and presenters in various academic settings, seminars, meetings, and conferences in order to organize their utterances, to interact with their audiences, and to transfer information in a meaningful way. In addition, findings would be useful for teachers and professors in giving some instructions on metadiscourse markers and in guiding students to apply these markers in their academic speech to improve their speaking ability. Furthermore, those who prepare materials for university students can benefit from the results of present study. They must apply more metadiscourse markers in their books to interact with their readers and to help them comprehend the author's intention more explicitly.

Hyland (2004) emphasized the significant role of metadiscourse as an analytical tool that depends on the context in which it occurs and claimed that the way the writers express their views, negotiate an argument, and interact with their readers is related to the norms and expectations of a particular disciplinary community. $\mathrm{He}$ also states that

metadiscourse offers teacher a useful way of assisting students toward control over disciplinary-sensitive writing practices. Because, it shows how writers engage with their topics and their readers, therefore, the exploration by students of metadiscourse in their own and published writing can offer useful assistance for learning about appropriate ways to covey attitudes, mark structure, and engage with readers (Hyland, 2004, p. 148).

According to Hyland (2005), teaching metadiscourse means making students sensitive to the rhetorical effects and features included in a given genre and community and providing enough resources for them to interact with their audiences in their own world. He emphasized the importance of metadiscourse in the classroom and believed that teaching metadiscourse to the students has three main advantages. First, students become aware of cognitive demands made by text for readers and also they can recognize the ways that help them to proceed. Second, teaching metadiscourse provides sufficient resources for the students to take a stance toward their ideas. Third, teaching metadiscourse helps students negotiate ideas with their audiences.

Concerning the great importance of metadiscourse markers, Kuhi, Asadollahfam, and Dabagh Anbarian (2014) suggested that particular attention must be paid to the concept of metadiscourse by language teachers and learners during their teaching and learning process. Making the students aware of the significant role of metadiscourse, help them become better listeners and speakers. When students inform that discourse includes propositional content and interactional elements, thus by following the speaker's line of argument they can comprehend the discourse better and by anticipating the listener's interaction with the content they can speak more comprehensibly.

Ahour and Entezari Maleki (2014) emphasized the role of metadiscourse learning in improving the students' speaking ability. They suggested that metadiscourse can be used as a strategy to take care of hesitations in speaking and to save time to think about subsequent sentences. They believed that the function of metadiscourse markers as fillers, change them to suitable tools for assessing the speaking ability of the students, and teachers 
Mahmoodian, H., \& Simin, S.

can take advantage of teaching metadiscourse to increase the quality of their students' speech.

\section{References}

Ahour, T., \& Entezari Maleki, S. (2014). The effect of metadiscourse instruction on Iranian EFL learner's speaking ability. English Language Teaching, 7(10), 69-75. https://doi.org/10.5539/elt.v7n10p69

Crismore, A., Markkanen, R., \& Steffensen, M. (1993). Metadiscourse in persuasive writing: A study of texts written by American and Finnish university students. Written Communication, 10(1), 39-71. https://doi.org/10.1177/0741088393010001002

Estaji, M., \& Vafaeimehr, A. (2015). A comparative analysis of interactional metadiscourse markers in the introduction and conclusion sections of mechanical and electrical engineering research papers. Iranian Journal of Language Teaching Research, 3(1), 37-56.

Faghih, E., \& Rahimpour, S. (2009). Contrastive rhetoric of English and Persian written texts: Metadiscourse in applied linguistics research articles. Rice Working Papers in Linguistics, 1, 92-107.

Fraser, B. (1988). Types of English discourse markers. Acta Linguistica Hungarica, 38(1-4), 19-33.

Fuertes-Olivera, P. A., Velasco-sacristan, M., Arribas-Bano, A., \& Samaniego-Fernandez, E. (2001). Persuasion and advertising English: Metadiscourse in slogans and headlines. Journal of Pragmatics, 33, 1291-1307. https://doi.org/10.1016/S0378-2166(01)80026-6

Ghaemi, F., \& Naderi Anari, N. (2014). Metadiscourse in lecture comprehension: A case study of Iranian learners. International Journal of Language Learning and Applied linguistic World, 6(4), 483-490.

Gholami, M., Tajalli, G., \& Shokrpour, N. (2014). An investigation of metadiscourse markers in English medical texts and their Persian translation based on Hyland's model. European Journal of English Language and Literature Studies, 2(2), 1-41.

Hyland, K. (1998). Persuasion and context: The pragmatics of academic metadiscourse. Journal of Pragmatics, 30, 437-455. https://doi.org/10.1016/S0378-2166(98)00009-5

Hyland, K. (1999). Talking to students: Metadiscourse in introductory course books. English for Specific Purposes, 18(1), 3-26. https://doi.org/10.1016/S0889-4906(97)00025-2

Hyland, K. (2000). Disciplinary discourses: Social interaction in academic writing. London: Pearson.

Hyland, K. (2004). Disciplinary interactions: Metadiscourse in L2 postgraduate writing. Journal of Second Language Writing, 13, 133-151. https://doi.org/10.1016/j.jslw.2004.02.001

Hyland, K. (2005). Metadiscourse: Exploring interaction in writing. London: Continuum.

Hyland, K., \& Tse, P. (2004). Metadiscourse in academic writing: A reappraisal. Applied Linguistics, 25(2), 156-177.

Kuhi, D., Asadollahfam, H., \& Dabagh Anbarian, K. (2014). The effect of metadiscourse use on Iranian EFL learners' lecture comprehension. In the Procedia social and behavioral sciences (Vol. 98, pp. 1026-1035). Urmia, Iran. https://doi.org/10.1016/j.sbspro.2014.03.513

Kuhi, D., \& Mojood, M. (2012). A contrastive study of metadiscourse in English and Persian editorials. The Journal of Applied Linguistics, 5(1), 137-162.

Rezaeizadeh, Z., Baharlooei, R., \& Simin, S. (2015). Interactive and interactional meta-discourse markers in conclusion sections of English master theses. International Journal of Research Studies in Language Learning, 4(4), 81-92.

Schiffrin, D. (2001). Discourse markers: Language, meaning, and context. In D. Schiffrin, D. Tannen \& H. E. Hamilton (Eds.), The handbook of discourse analysis (pp. 54-75). Malden, MA: Blackwell Publishers.

Simin, S., \& Tavangar, M. (2009). Metadiscourse knowledge and use in Iranian EFL writing. Asian EFL Journal Quarterly, 11(1), 230-255.

Swales, J. (1990). Genre analysis: English in academic and research settings. Cambridge: Cambridge University Press.

Zarei, G. R., \& Mansoori, S. (2011). A contrastive study on metadiscourse elements used in humanities vs. non humanities across Persian and English. English Language Teaching, 4(1), 42-50. https://doi.org/10.5539/elt.v4n1p42 